\title{
COLLABORATIVE WRITING USING GOOGLE DOCS IN PRIMARY EDUCATION: DEVELOPMENT OF ARGUMENTATIVE DISCOURSE
}

\author{
Chrysoula ZIOGA \\ ORCID: 0000-0001-7444-1528 \\ 3rd Experimental Primary School of Evosmos \\ Thessaloniki, GREECE \\ Dr. Konstantinos BIKOS \\ ORCID: 0000-0002-8616-8626 \\ School of Philosophy and Education \\ Aristotle University \\ Thessaloniki, GREECE
}

Received: 25/07/2019 Accepted: 02/09/2019

\begin{abstract}
The aim of the present study was to determine the effect of a collaborative writing programme through the Google Docs writing tool on the production of argumentative discourse within the framework of Modern Greek Language teaching. The participants were 23 pupils in Year 5 who received a six-month period teaching intervation (two hours per week) that included collaborative writing activities of argumentative discourse. Prior to the beginning, and following the end of the programme the performance of all participants on argumentative discourse writing skills was evaluated with a 13-criteria Rubric scale. The results of the pairedsample t-tests showed a statistically significant difference between pre- and post tests in the majority of the criteria and the total scores of the rubric. It is therefore concluded that, the use of a Web platform may positively contribute towards the enhancement of argumentative discourse writing skills of pupils in Year 5 of Primary Education.
\end{abstract}

Keywords: Argumentation, collaborative discourse, Google Docs.

\section{INTRODUCTION}

The production of writing, a teaching process that requires pupils to become familiar with its various stages of implementation, is one of the primary targets of education according to the Greek Interdisciplinary Common Curriculum Framework (Pedagogical Institute, 2003). In particular, Modern Greek Language teaching in Primary School, aims at the development of a pupil's ability not only to handle its written and verbal forms adequately but also confidently, consciously, responsibly, effectively and creatively, thus actively participating in school as well as, in society. Indeed, it is essential that the most "powerful" types of writing (e.g. argumentation, essay, informative text etc) which apply in socio-cultural forms of power are immediately taught to the children, as most of these properties are outside the span of their immediate experience. Narration texts, as the main representative model of narrative discourse, contrary to other forms, continue their dynamic presence in the new school textbooks of the Modern Greek Language. The entry of persuasive argumentative texts as a representative sample of directive discourse, come in to overturn the one-dimensional teaching practice (Dinas \& Xanthopoulos, 2007). Teaching the Modern Greek Language, in particular teaching writing in Year 5, aims at the cultivation and "development of a pupil's ability to communicate accurately and effectively in writing, using form and style appropriate to the occasion" (Pedagogical Institution, 2003). Furthermore, the basic objective is for pupils to become familiar with a range of texts; amongst which are argumentative texts, which help pupils satisfy their practical, emotional, spiritual and social needs. 


\section{COLLABORATIVE WRITING AND ARGUMENTATION}

Argumentation emerges from a need to teach pupils thinking skills. It is of utmost importance for pupils, in a democratic society to be able to develop critical thinking and that also includes their ability to assess arguments and counter-arguments in relevance to a variety of modern-day subjects (e.g. genetically modified food, solutions to global warming, etc) (Halpen, 1998). In 1958 the English philosopher Stephen Toulmin, dealt with the "primal confusion" of production and induction, suggesting his own model of analysis of argumentation called "The Toulmin model of argumentation". This model found fertile ground in the teaching of verbal communication and it has influenced the schoolbooks which deal with the meaning of argument. Argumentation, whether it concerns traditional methods (face-to-face argumentscounterarguments and written argumentative texts) or the more modern approach which is based on the production of argumentative text via computers, helps us understand the way that the argument functions within an educational framework (Andriessen, 2006).

Collaborative writing appears to be particularly productive in the writing of argumentative text. Pupils either become involved in a social procedure to co-construct and critique arguments or negotiate solutions on general problems and promote knowledge, in their attempt to bridge any conflicts that may arise (Golanics $\&$ Nussbaum, 2008). It is also educationally important since it helps pupils draw connections on their ideas, form alternative conceptions and reflect on the meaning and the evidence of these ideas by causing a conceptual change, a better subject matter understanding, as well as promoting complex and critical thinking. For example, pupils may collaborate or disagree by organizing and grouping arguments and counter arguments, creating discourses, using role-play, planning and executing a work-plan in common. These are good practices which are promoted through teaching either in small groups or in larger classes (Matsagouras, 2000). The results on collaborative argumentation for individual performances have also proved to be significant, and in particular for the introverted pupils, who find adversarial discourse threatening; the threat being that they might fail an argument and this would damage their self-impression on others (Nussbaum, 2008).

\section{TEACHING APPROACH USING ICT}

Nowadays there is a rapid technological evolution which the educational community cannot ignore. The emergence of new Web 2.0 tools can allow for activities to be saved for later use and can also substitute a number of high level human skills. Those tools have become an integral part of the daily work and family environment, as well as for the production of activity and quality time (Depover, Karsenti, \& Komis, 2010). A major part of this New Information and Communication Technologies (ICT) has already been put into teaching practice by primary school teachers changing the traditional teaching approach. A Traditional teaching method can be defined as a procedurally teaching method in which the teacher displays, explains, and discusses the content of the Greek language to Year 5 students without the use of ICT. In relation to the subject of Modern Greek Language, integration of ICT may act as a better and more attractive method of teaching. In the New Pilot Study Programs (2011), for teaching the Modern Greek Language and Literature in Primary Education, stress is placed on the use of the ICT in teaching and learning, as well as in the value of collaboration. The ultimate target is considered to be the development of language skills, critical and digital literacy and, also, the reinforcement of pupils' creativity, critique and research ability, according to the social constructivism and collaborative learning theory (Newby, Stepich, Lehman, \& Russel, 2009).

The web application Google Docs is a digital tool which helps pupils work in a collaborative learning environment. Sharp (2009) claims that this collaborative text-processing tool allows a group of people to process a document simultaneously; that is writing and monitoring, while at the same time, changes are made by the others. Collaborative writing using Google Docs comprises of coordinated collaboration, which allows participants to monitor all other participations while writing a text themselves, as it opposes any individual working independently of the other and then all individual work being combined into one final mutual document. Thus, it promotes a new collaborative working method which generates collective content, facilitates collaborative writing and group discussions. In this manner, Google Docs assist in creating a dynamic, collaborative learning environment where knowledge is gained through open discussions and exchange of ideas, via collaborative structure and active participation of the members (Su \& Beaumont, 2011). 


\section{LITERATURE REVIEW}

Research on collaborative discourse teaching using an electronic environment in Greece was conducted by Antoniou (2001) and it concerned a sample of 74 pupils at the American College of Thessaloniki. In this research, collaborative learning was adopted for the teaching of argumentative writing in classes connected to computer networks and using Daedalous Intergrated Writing Environment - DIWE as their writing collaborative tool. The results of the study showed that the use of ICT could reinforce teaching in the production of written discourse.

Following the reformation of Greek Curriculums for Elementary and Secondary Education in 2011, where the issue of teaching productive discourse using ICT arose, a small number of researches concerning the teaching of argumentative discourse through collaborative tools for students in Secondary Education were noted. More specifically, Delis (2015) studied and analyzed an intervention, which was implemented in one unit of the Modern Greek Language syllabus taught in Year 3 of Junior High School, using the electronic learning environment platform Moodle, where the students followed collaborative strategies in text production. The research pinpointed the potential for the inclusion of collaborative learning through an electronic environment, since its results demonstrated reinforcement in students' language ability, in their digital literature, and also in other learning quality characteristics, such as collaboration, autonomy, authentic learning etc. In addition, research carried out on a sample of 39 students of Year 3 of Junior High School using Google Docs showed that collaborative writing in an electronic learning environment could be effective and, thus be introduced into the educational teaching practice of written discourse in Secondary Education (Drakou, 2014). A similar research but for Foreign Language teaching was carried out on a sample of 19 students in Junior High School, using electronic tool Google Docs (Exarchou, 2016). From the results it was apparent that Documents Google Docs could function as a tool in collaborative writing which could create an environment for the motivation of students, while stimulating their creativity as they are gradually led towards autonomy. The researcher claimed that her findings could be an aspect of interesting factor to help teachers to acquire insight into the procedures concerning the learning of a foreign language.

Various researches have been carried out in higher education concerning collaborative learning in an electronic environment using Google Docs (Brodahl, Hadjerrouit, \& Hansen, 2011; Suwantarathip \& Wichadee, 2014; Zhou, Simpson, \& Domoci, 2012). Their results showed that the method of collaborative writing, this particular feature of Google Docs, motivated the participants to learn more effectively and thus to make more of an effort in argument production. Also, it was ascertained that the students could perceive the importance of Google Docs as a useful collaborative tool while operating in small working groups thus reinforcing active participation, group interaction and the building of a common knowledge, leading to an improvement of writing skills. Additionally, the participants claimed that the actual promise of argumentative discourse via computers can become a reality in training where, they will not need to produce answers but only arguments in order to gain autonomy and consequently achieve dynamic learning. In a study by Chryssafidou (2014) carried out on a sample of 16 students, whose purpose was the comparison of computer argument diagrams to paper ones, it was evident that the computer presents more challenges to the user while there is also an improvement in the argumentative writing skills essential for the students. Moreover, a significant number of researchers and educators have used argumentative practices for teaching the content of school subjects, apart from Language, such as Science (Driver, Newton, \& Osborne, 2000), Mathematics (Lampert, Rittenhouse, \& Crumbaugh, 1996; Metaxas, 2011), History and Social Science (De La Paz, 2005). In these practices students had participated in an on-line environment constructing arguments and counter-arguments.

In general, the interest for the development of argumentative discourse in Greece appears to be quite low. While there are particular references to students' development regarding critical thinking through argument, the teaching of argumentative discourse occurs at a very low degree in the last three years of Primary Education to a much higher degree in Secondary Education. Furthermore, even though debating practices have been adopted and debate competitions are organized in our country, this only concerns Secondary Education. In Primary Education, debates only take place for Foreign Languages. 


\section{PURPOSE OF THE STUDY}

The purpose of the present study was to explore the effectiveness of collaborative writing through the web collaborative writing tool Google Docs for the production of argumentative discourse within the framework of Modern Greek Language teaching in Year 5 of Primary School. More specifically, the production of full argumentative texts was pursued by following the structural elements of argumentation. The pedagogical design and application of the programme was based on the theories of collaborative learning, constructivism, learning activities and distributed knowledge. Additionally, the communicative - text-centred approach of the language and the need for the utilization of web tools as an innovation in the educational procedure were taken into consideration. To examine the effectiveness of Web 2.0 tools in the teaching of Modern Greek Language for pupils in Primary Education Year 5, the following research question was set:

What would be the effect of a teaching programme with the use of a collaborative web tool on the production of written argumentative discourse?

\section{METHOD}

The pre- post intervention evaluation design was adopted to identify the effectiveness of the Google Docs environment in development of pupils' achievement in argumentative discourse.

\section{Participants}

The sample for this study consisted of 23 Year 5 pupils (11 boys and 12 girls) who randomly selected from an Experimental State school in Northern Greece. The participants came from various socio-economic backgrounds and had basic knowledge of computing and social networking experience. Also they had access to the internet both at home and at school.

\section{Group Formation}

Pupils were distributed into six groups ( 5 groups of four members and one group of three members). The groups were formed according to the pupils' writing performance so that they would be diverse. This method of distribution was selected as research has shown that group diversity can secure a variety of stimuli, reinforce social learning, and also discourage marginalization of weaker pupils (Kanakis, 2001). Consequently, the groups should be formed to include members whose skills will not differ to a great degree but will rather complement each other. Member roles (coordinator, leader, secretary, reader) were clearly defined and changed for every new text written by the pupils, so that manner each pupil could benefit from each role.

\section{Organization of Lessons}

Initially, at the beginning of the programme, all pupils were taught the concepts of argument and argumentation. They were then taught the structure/organization of an argumentative text through a structured text as follows: a) Introduction/Prologue (pre- announcement/presentation of an issue/opinion or a problem), b) Data (use of examples and evidence) c) Justification/refutation (use of arguments/counter argument) and d) Conclusion/Epilogue (Ending/suggestions). The teaching was concerned with the reinforcement of pupils' skills to identify arguments in a text, to comprehend their target, to use corresponding arguments and become persuasive through role-play, to write their arguments in a paragraph with a specific topic sentence, and to identify specialised vocabulary for argumentation.

Then the pupils were formed into groups using the collaborative learning strategy and the group collaboration method was applied for the production of written discourse. Throughout the teaching of written discourse production, the three stages suggested by Flower and Hayes (1994) were applied.

More analytically, each stage included the following:

a. Pre-writing: In this stage the activities that took place were: structured discourse-Debate, text comprehension questions, paragraph comprehension, diagram designing, vocabulary exercises, short paragraph production, summarizing and finally, writing-text style exercises. 
b. Writing: the pupils applied the discourse production method in the computer lab, where they were divided into four groups of four, and one group of three, sitting at the computer desk in pairs, and using collaborative tool Google Docs. They also used the diagram prepared in advance for the graph space provided. Document Google Docs was distributed to each pupil's e-mail account, so that they all had access to the text.

c. Post-writing: the group of writers/pupils while maintaining their distributed roles, reviewed/ improved their text by using all the given data based on the text processing strategy, so as to achieve the final format and improvement of their text. In particular, according to the Revised Protocol of Argumentative text (Varsamidou \& Spantidakis, 2015) the coordinator organised the group members as such in order for them to edit the in text regarding content, structure, effectiveness, style and language.

\section{Data Collection and Analysis}

Prior to the commencement of this program, the pupils were asked to produce a draft of the argumentative text in the form of an essay, as a pre-test, in order to determine their initial argumentative writing skills. A six month teaching intervention followed, which included two teaching hours per week. The teaching intervention took place in the classroom but also in the school's computer lab using $12 \mathrm{P} / \mathrm{Cs}$. The topics given to the pupils included, the argumentation concerning the choice of means of mass transportation or car, the possibilities offered or the problems that arise with the use of a $\mathrm{P} / \mathrm{C}$ in the teaching process, allowing dogs permission in buildings, individual or team sports, the use of printed or electronic books.

Following the end of the programme, as a post-test, the pupils were asked to produce a new argumentative text of an equal level of difficulty as the initial text.

All written texts produced by the pupils were assessed by two evaluators, who are $\mathrm{PhD}$ holders in the Teaching of the Modern Greek Language. The evaluators were trained in the use of the rubric, initially by studying the criteria of the tool and its categories, and by discussing and resolving any queries. Each of the evaluators assessed five texts independent of the present research where the agreement between them, concerning the inter-rater reliability was determined as much for each criterion as for the total Rubric. To determine the intra-rater reliability, each of them randomly re-assessed two of the previous texts one month later.The results showed that the intra-rater reliability on each criterion for every evaluator was .98 . The inter rater reliability for both assessors for each of the criteria in the Rubric ranged between -.90 to 1.00. In the present study their agreement concerning the criteria ranged from -.92 to .97 .

\section{The Scale}

A scoring rubric was used for the evaluation of the pupils skills on argumentative text writing, a method of formative and summative assessment. The rubric provides quality criteria and a grading system which evaluates the performance of each pupil. The evaluation technique of the rubric includes a) performance evaluation criteria, which provide the appropriate requirements for a task to be considered correct $\mathrm{b}$ ) task performance levels, including a numeric scale and c) a detailed description of criteria in each level (Andrade, 2001).

Two experts in Modern Greek Language teaching evaluated the content validity of the rubric for accuracy, significance and validity accordingly. According to the feedback and suggestions of the experts, some corrections were made as to the number of the performance level and the different characteristics of each level. The final rubric for the evaluation of the argumentative text included the following 13 criteria: $1^{\text {st }}$ claim/thesis of issue, $2^{\text {nd }}$ support of issue, $3^{\text {rd }}$ counterclaim, $4^{\text {th }}$ evidence, $5^{\text {th }}$ conclusion, $6^{\text {th }}$ number of arguments, $7^{\text {th }}$ vocabulary, $8^{\text {th }}$ structure, $9^{\text {th }}$ effectiveness, $10^{\text {th }}$ flow, $11^{\text {th }}$ content, $12^{\text {th }}$ length of the text, $13^{\text {th }}$ research. Each of the above criteria included the performance of the learner on a 5-point rating scale: 5=Excellent, 4=Very Good, 3=Good, 2=Average, 1=Low. The possible score of the rubric ranged between 1 to 5 in each criterion and from 13 to 65 in total. 


\section{FINDINGS}

According to the results of the descriptive statistics the performance of the participants on each rubric criterion and also in its total is shown on Table 1.

Table 1. Means, standard deviations and statistical indexes of paired samples t-tests for each criterion and the total of the Rubric

\begin{tabular}{|c|c|c|c|c|c|c|}
\hline \multirow{2}{*}{ Criteria } & \multicolumn{2}{|c|}{ Pre-test } & \multicolumn{2}{|c|}{ Post-test } & \multirow[b]{2}{*}{$\mathrm{t}$} & \multirow[b]{2}{*}{$\mathrm{p}$} \\
\hline & M.O. & T.A. & M.O. & T.A. & & \\
\hline $1^{\circ}:$ Claim & 3.38 & 1.63 & 3.62 & 1.46 & -.79 & .437 \\
\hline $2^{\circ}:$ Support & 3.14 & 1.01 & 3.95 & 1.11 & -3.6 & $.002^{\prime \prime}$ \\
\hline $3^{\circ}$ : Counterargument & 1.19 & .51 & 3.38 & 1.5 & -7.36 & $.000^{\prime \prime}$ \\
\hline $4^{\circ}$ : Evidence & 2.24 & .89 & 3.52 & 1.4 & -4.15 & $.000^{\prime \prime}$ \\
\hline $5^{\circ}:$ Conclusion & 3.52 & 1.66 & 3.48 & 1.72 & .132 & .897 \\
\hline $6^{\circ}:$ Number of Arguments & 2.62 & .74 & 3.81 & 1.28 & -4.86 & $.000^{\prime \prime}$ \\
\hline $7^{\circ}:$ Vocabulary & 2.52 & .60 & 3.19 & 1.03 & -4.18 & $.000^{\prime \prime}$ \\
\hline $8^{\circ}:$ Structure & 2.57 & .75 & 3.29 & 1.00 & -4.18 & $.000^{\alpha}$ \\
\hline $9^{\circ}:$ Effectiveness & 2.52 & .75 & 3.62 & 1.11 & -5.04 & $.000^{\prime \prime}$ \\
\hline $10^{\circ}:$ Flow & 2.43 & .75 & 3.38 & 1.02 & -4.26 & $.000^{\alpha}$ \\
\hline $11^{\circ}:$ Content & 2.43 & .59 & 3.29 & 1.05 & -3.87 & $.001^{\prime \prime}$ \\
\hline $12^{\circ}$ : Length & 2.11 & .77 & 4.14 & 1.15 & -7.79 & $.000^{\alpha}$ \\
\hline $13^{\circ}:$ Research & 1.00 & .00 & 3.14 & 1.93 & -5.09 & $.000^{\prime \prime}$ \\
\hline Total & 31.67 & 8.75 & 45.81 & 14.65 & -5.83 & $.000^{\alpha}$ \\
\hline
\end{tabular}

Note." $p<.01$

To determine the existence of statistically significant differences between pre- and post-test on the participants' performance regarding the criteria and the rubric total, paired-sample t-tests were applied with significance level $\mathrm{p}<.05$. Data analysis showed a statistically significant improvement on the rubric's total scoring $(\mathrm{t}(20)=5.83, \mathrm{p}<.001)$ between the pre- $(\mathrm{M}=31.67, \mathrm{SD}=8.75)$ and the post-test $(\mathrm{M}=45.81, \mathrm{SD}=14.65)$. Also, a statistically significant improvement was established on each rubric's criterion performance, except for the $1^{\text {st }}$ and $5^{\text {th }}$ criterion as presented on Table 1.

\section{DISCUSSION AND CONCLUSION}

In the present research a teaching program on Modern Greek Language for Year 5 of Primary Education was applied by means of collaborative learning environment Google Docs. The aim of the programme was to evaluate the results of collaborative writing using the forenamed tool for the improvement of the writing skills on argumentative discourse. The pupils through a series of collaborative writing activities cooperated for the final production of argumentative texts (reports, articles, essays etc). The evaluation of the structural elements of written argumentative text was conducted by the use of an analytic rubric (scale). From the results of the research it appeared a significant improvement in nearly all the structural elements of written argumentative discourse.

More specifically, after completion of the programme the pupils had improved significantly in almost all structural elements of written argumentative text as these were assessed by the use of the Rubric. In its total score, the mean of the class prior to the intervention ranged between "Average" (2) and "Good" (3). At the end of the intervention the class had moved one level higher as it achieved "Good" (3) and "Very Good" (4). Following the teaching intervention, pupils had improved their ability to organize argumentative texts in a manner that demonstrated the structure as well as their collaborative progress. The arguments and the defined structure of argumentative texts, as taught during the intervention, in contrast to conventional teaching as set by the Syllabus, appears to have led pupils to a further improvement of text structure and to the development of their writing abilities. Arguably, the multiple writing attempts of written arguments and 
the constant constructive feedback of the written work from the whole class may possibly have reinforced their critical and conceptual ability.

In reference to the effect of the program on each structural element of the written argumentative discourse, as illustrated by the rubric's criteria, the results led to a positive response for all the criteria except for the $1^{\text {st }}$ and $5^{\text {th }}$ where no improvement was observed. More specifically, the $1^{\text {st }}$ criterion which concerns claim/thesis of the writer (inclusion of a strong argument which supports this view), did not demonstrate a significant difference after the intervention as neither did the $5^{\text {th }}$ criterion regarding the conclusions. Students' performance varied between "Good" and "Very Good" in the pre-test and was maintained at the same levels after completion of the program. It appears that, these criteria did not present any difficulty to the pupils, as pupils at this age are able to write a correctly formed introduction and come to a conclusion, as the structure of productive discourse (introduction/prologue, main body, conclusion) is taught in previous years.

Generally, the pupils better comprehended the structural elements of argumentative discourse, such as the introduction of strong logical arguments to support issues, and argument-counterargument refutations. In particular, the production of counterarguments (arguments for the conversion) was almost absent (level "low") in the pre-test while after the program implementation there was a significant improvement (level between "good" and "very good"). The pre-test finding supported the statement of Matsagouras (2002) that pupils at the age of 11 are unable to find opposing arguments to the proposed solution because they do not have the maturity to disprove the argument by counterargument. However, according to the results of the present research, after pupils' guidance and development of their collaborative skills in written exercises for argument-counterargument, they are capable to achieve the mechanism for the refutation of arguments.

Moreover, learners seemed to better understood the making use of examples, information and evidence to support an issue and to reinforce an argument. Also, an increase in the number of arguments and an improvement concerning the morphology of the text (grammar, syntax, coherence/cohesion) was observed. The continuous contact with the articles they had been given and the techniques of linking words-phrases for introduction of arguments appear to have facilitated an enhancement on the text's morphology, vocabulary and also, effectiveness (argumentation, persuasiveness). Familiarity with textual and expressional structures which ensure coherence and cohesion in the text led to a quality improvement in argumentative writing as can be seen from the content, formation, flow, the syntax structure and the length of the final text product. Correspondingly, the use of third person provided the writer with a sense of detachment which gave objectivity to the text and thus, prompted the reader of the text to accept the opinion of the writer as it was well-documented in an accurate and scientific manner. Lastly, a significant improvement was demonstrated in the length of the text and the resources available. The final texts produced were visibly more extended in length due to collaborative writing and its resources as the pupils made use of the internet.

Finally, argumentation as a teaching objective appears to have empowered the relationship pupils have with language, as they came into contact with argumentative discourse. Practice and familiarity with new syntax, structural and expressional texts, which characterize persuasive text, their morphology and style, facilitated the effective conquering of the language. In addition, the pupils comprehended how useful argumentative texts are and their connection to other teaching objectives and, to an extent, their function in everyday life. The writing skills of the pupils improved since they had several opportunities to produce written arguments and argumentative discourse. At the same time, collaborative writing activities using the web tool transformed the procedure into a game.

The findings of the present study regarding the use of Google Docs in the production of argumentation text are in consistent with previous researches which have been implemented in the teaching of Greek language in secondary education (e.g., Antoniou, 2001; Drakou, 2014; Delis, 2015; Exarchou, 2016). Also they are consistent with results of studies with participants from the tertiary education (e.g., Brodahl, Hadjerrouit, \& Hansen, 2011; Suwantarathip \& Wichadee, 2014; Zhou, Simpson, \& Domizi, 2012) and for teaching the content of school subjects other than Language (e.g., Driver, Newton, \& Osborne, 2000; Metaxas, 2011; De La Paz, 2005). The investigations concerning primary education in Greece focused on the refinement of argumentation discourse without the Web2.0 writing tools (Egglezou, 2016; Sifaki, 2008). So the results of the present study are the first evidences for the positive effects of the ICT use in the production of written discourse. 
A limitation of this research study is the limited number of participants. Further research is required with a larger sample and from several areas and various types of schools. Furthermore, it would be useful to include a retention test, so as to ascertain whether an argumentative discourse teaching programme using collaborative tool Google Docs leads to learning. Additionally, further research is suggested for a comparison of the effectiveness of the present intervention with a second experimental group which would follow a collaborative argumentation writing method without a web tool and a control group which would follow argumentation skills' teaching using activities from the textbook.

\section{BIODATA and CONTACT ADDRESSES of AUTHORS}

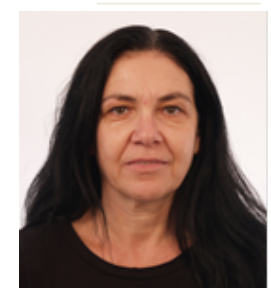

Chrysoula ZIOGA, is a general teacher with many years of professional experience. She currently works in 3rd Experimental Primary School of Evosmos in Thessaloniki, Greece. She obtained her Master of Science degree in Sciences of Education and Lifelong Learning in July 2017. Her academic interest areas are mainly focused on the integration of technology in education and the use of educational technologies in language learning. Digital learning objects, distance education and social media are also included in her interests.

Chrysoula ZIOGA

3rd Experimental Primary School of Evosmos

Address: Directorate for Elementary Education, 56224, Thessaloniki, Greece

Phone: +30 6974146591

E-mail: xrysoulazioga@gmail.com

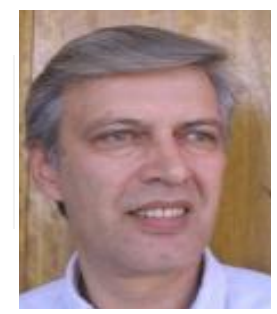

Dr. Konstantinos BIKOS, is a Full Professor in "Educational Schooling and Information Communication Technologies in Education" and head of the School of Philosophy and Education in the Aristotle University of Thessaloniki (Greece). He is directing the "Microteaching Laboratory", while his teaching and research interests include Human Relations in Educational Settings, the use of Information Communication Technologies in Education and Teachers' Training.

Prof. Dr. Konstantinos BIKOS

Address: Aristotle University of Thessaloniki School of Philosophy and Education, 54124 Thessaloniki University of Thessaloniki (Greece)

Phone: +302310.99.7385

E-mail: bikos@edlit.auth.gr

\section{REFERENCES}

Andrade, H. G. (2001). The effects of instructional rubrics on learning to write. Current Issues in Education, 4(4) http://cie.ed.asu.edu/volume4/number4

Andriessen, J. (2006). Collaboration in computer conferencing. In A. O’Donnell, C. Hmelo-Silver, \& G. Erkens (Eds.), Collaborative learning, reasoning, and technology. (pp. 197 - 231). Mahwah, NJ: Erlbaum.

Antoniou, L. (2001). Argumentative writing and computers in an EFL environment: the Greek paradigm. (Master's Dissertation). Aristotle University of Thessaloniki, Thessaloniki http://thesis.ekt.gr/ thesisBookReader/id/22774\#page/292/mode/2up

Brodahl, C., Hadjerrouit, S., \& Hansen, N. K. (2011). Collaborative writing with Web 2.0 technologies: education students' perceptions.

Chryssafidou, E. (2014). Argument diagramming and planning cognition in argumentative writing (Doctoral dissertation, University of Birmingham). 
De La Paz, S. (2005). Effects of historical reasoning instruction and writing strategy mastery in culturally and academically diverse middle school classrooms. Journal of Educational Psychology, 97, 139156.

Delis, F. (2015). Collaborative Learning supported by digital enviromental. Case study in teaching language in year 3 of Junior High School. (Master's Dissertation). University of the Peloponnese, Corinth.

Depover, C., Karsenti, T., \& Komis, B. (2010). Teaching with the use of Technology, promoting learning, developing skills. Klidarithmos Publications, Athens.

Dinas, K. \& Xanthopoulos, A. (2007). The teaching of the production of written language in the new books of Greek language for Primary School (classes C, D, R \& D). In Proceedings of the Conference: Language, Thought and Practice in Education, 19-21 October 2007. Ioannina: Regional Directorate of Education of Epirus.

Drakou, k. (2014). Speech production using collaborative tools: A study in Modern Greek Language III. (Master's dissertation). University of Peloponnese, Corinth.

Driver, R., Newton, P., \& Osborne, J. (2000). Establishing the norms of scientific argumentation in classrooms. Science education, 84(3), 287-312.

Egglezou, F. (2016). The argumentation in the Cross Curricular/Thematic Framework-Programs of Study (Syllabi) of the Primary and Secondary Education: Perspectives and Suggestions. In M. Korda, I.O. Despi, F. Egglezou, Ch. Koronaiou, M. Lada, V. Loutrianaki (Eds), $1^{\text {st }}$ Panhellenic Conference in Curricular-School manuals: From the past to the present and future, 4-6 March 2016 (pp. 213214). Athens, Greece.

Exarchou, M.A. (2016). Google Documents: A useful tool to develop collaborative writing by increasing students' creativity and motivation in an EFL Context. (Master's dissertation). Hellenic Open University, Patra.

Flower, L., \& Hayes, J. R. (1994). The cognition of discovery: Defining a rhetorical problem. Landmark essays on writing process, 63-74.

Golanics, J. D., \& Nussbaum, E. M. (2008). Enhancing online collaborative argumentation through question elaboration and goal instructions. Journal of Computer Assisted Learning, 24(3), 167-180.

Halpern, D. F. (1998). Teaching critical thinking for transfer across domains: Disposition, skills, structure training, and metacognitive monitoring. American psychologist, 53(4), 449.

Kanakis, N.I. (2001). The Organization of Teaching-Learning with Working Groups Theoretical Foundations and Practical Application. Athens: Typothito Publications

Lampert, M. L., Rittenhouse, P., \& Crumbaugh, C. (1996). Agreeing to disagree: Developing sociable mathematical discourse. In D. R. Olson \& N. Torrance (Eds.), Handbook of human development in education (pp. 731-764). Cambridge, MA: Blackwell.

Matsagouras, H.G. (2000). Group Collaborative Teaching and Learning: Theory and Practice of Teaching. Athens: Grigoris.

Metaxas, N. (2011). Argumentation analysis of mathematics teachers as a tool for studying their professional knowledge. (Master's dissertation) National and Kapodistrian University of Athens, Athens.

Newby, J.T., Stepich, A.D., Lehman, D.J., Russel, D.J. (2009). Educational Technology for Teaching and Learning. Thessaloniki: Epicenter Publications.

New Pilot Study Programs (2011). Scientific Field: Language-Literature. Retrieved on January 20, 2016, from http://ebooks.edu.gr/new/ps.php

Nussbaum, E. M. (2008). Collaborative discourse, argumentation, and learning: Preface and literature review. Contemporary Educational Psychology, 33(3), 345-359.

Pedagogical Institute (2003). A Cross Thematic Curriculum Framework for Compalsory Education. Retrieved from http://www.pi-schools.gr/programs/depps/index_eng.php 
Sharp, V. (2009). Computer education for teachers: Integrating technology into classroom teaching (6 $6^{\text {th }}$ ed.). Hoboken, N.J.:John Wiley.

Sifaki, A. (2008). Argumentation Argumentation: the Argumentative speech in Elementary. An empirical survey. (Master's Dissertation). University of the Peloponnese, Patra.

Su F., \& Beaumont C. (2010). Evaluating the Use of a Wiki for Collaborative Learning. Innovations in Education and Teaching International. 47(4), 417-431. https://www.researchgate.net/ publication/232853690_Evaluating_the_use_of_a_wiki_for_collaborative_learning

Suwantarathip, O. \& Wichadee, S. (2014). 'The Effects of Collaborative Writing Activity Using Google Docs on Students' writing abilities'. TOJET: The Turkish Online Journal of Educational Technology, 13(2), (148-156). Retrieved December 03, 2015 from http://www.tojet.net/articles/v13i2/13215. pdf

Varsamidou, D. \& Spantidakis, I. (2015) Teaching and learning of the written speech. Athens: Gutenberg Publication

Vygotsky, L. S. (1978). Mind in Society. The Development of higher Psychological Processes. Cambridge, MA: Harvard University Press.

Zhou, W., Simpson, E., \& Domizi, D. (2012). Google Docs in an out-of-class collaborative writing activity. International Journal of Teaching and Learning in Higher Education, 24(3), 359-375. 